\title{
The Process of Democratic Breakdown: Controlling Information While Evading Term Limits
}

\author{
JUNHYEOK JANG* \\ University of California, Merced
}

\begin{abstract}
Politicians often erode democratic institutions to consolidate their personal power through acts like term limit evasions. Violations of fundamental constitutional arrangements, so-called "bright line" institutions, are often expected to result in antigovernment opposition. Then how do leaders evading term limits extend the term and keep their office? I argue that political leaders strategically prevent protests after the initiation of term limit evasions by limiting the free flow of information that is imperative for potential dissidents to collectively mobilize against a leader. Using difference-in-differences with matching for Time-Series Cross-Sectional data, I show that term limit evasions are followed by a marked decrease in a country's freedom of expression and it is more salient in autocracies than in democracies. In addition, using Venezuela as an example, I provide micro-evidence of information control by investigating how topics of opposition media change after termlimit evasion. Automated text analysis shows that a leader evading term limits not only censors threatening political information but also induces the media to offer distracting and apolitical information.
\end{abstract}

*Ph.D. Candidate in Political Science. Email: jjang23@ucmerced.edu 


\section{Introduction}

Democracies are eroding and authoritarian rule is being further entrenched in many parts of the world. Presidents elected by the public consolidate personal power by altering existing fundamental political institutions, such as presidential term limits. To name a few recent cases, Evo Morales in Bolivia (2017), Abdel Fattah El-Sisi in Egypt (2019), and Vladimir Putin in Russia (2020) have extended or removed term limits. Even Donald Trump once made a joke about extending term limits in the United States. ${ }^{1}$ Leaders who change such fundamental and brightline political institutions are supposed to confront social opposition. But as the above examples suggest, many leaders do try to evade term limits and prolong their power. How did they extend their term in the face of potential public opposition and protest movements?

More specifically, term limits clearly stated in a constitution allow people to form a mutual expectation that an incumbent will step down after their terms are over, regardless of competitiveness and popularity. This expectation incentivizes people to avoid costly protests and acquiesce until the incumbent's term is over. However, a term limit evasion breaks this expectation and induces dissidents to resent the government. By term limit evasion, I mean the process of a leader circumventing term limits, which ranges from an initial proposal to actual constitutional reform. In the early stage of a term limit evasion, a leader needs to deal with immediate negative responses from dissidents. The incumbent's compliance with term limits is readily observed by everyone, compared to other constitutional arrangements. As such, if a leader simply attempts to ignore the constitutional constraint without clever strategies, that noncompliance may serve as a focal point that facilitates massive anti-government movements from dissidents. Furthermore, a leader who circumvented a previous constitution may face longterm challenges from dissidents. A term limit evasion provides potential dissidents with a new environment in which acquiescence no longer automatically leads to the leadership change. In the post-evasion world, a leader may become vulnerable to dissent more than before as citizens

\footnotetext{
${ }^{1}$ Responding to Xi Jinping's term limit removal, Trump said "he's now president for life... I think it's great. Maybe we'll have to give that a shot someday.” Kevin Liptak. “Trump on China's Xi consolidating power: 'Maybe we'll give that a shot some day’” CNN (March 4, 2018). https://cnn.it/2BzG17Y
} 
become impatient with wrongdoings perpetrated by the incumbent.

I contend that political leaders, after the initiation of term limit evasion, increase restriction on the free flow of information to make coordinated opposition difficult, thereby preventing anti-government movements. Without sufficient freedom of expression, citizens have difficulty communicating with each other to assess their interpretations about the leader's actions, learn about the prevalence of social grievances against the leader, and discuss the best course of action (e.g., through street mobilization or institutional channels), including logistical details. Thus, I first expect to see a less free flow of information after the initiation of term limit evasion. This decline, however, would be less salient when a country has consolidated democratic institutions because curtailing the rights of people as a preventive measure without an actual dissent will be more likely to backfire (Ritter and Conrad 2016).

To test these hypotheses, I leverage difference-in-differences with matching for time-series cross-sectional (TSCS) data (Imai, Kim and Wang 2020), along with data from 1960 to 2010 on presidential or semi-presidential regimes, where a president enters office with term limits (Baturo 2014). This newly-developed estimation strategy reduces endogeneity problems and makes a treatment condition as-if randomly assigned by comparing each treatment with matched control groups that share the same history of treatments and a similar level of covariates. The result shows that the freedom of expression decreases significantly after the initiation of term limit evasion and its decrease is more salient in autocracy than in democracy.

If leaders evading term limits control information to stymie protests, what might be a specific strategy of information control? Building on the literature on information control (e.g. De Angelis and Vecchiato 2018, Roberts 2018, Shadmehr and Bernhardt 2015), I expect a term limit evasion will be followed by more distracting apolitical information in the media without any increase in political and sensitive information after a term limit evasion. Since a term limit evasion is one of the most salient and crucial political events, privately-owned media seeking greater readership would be incentivized to focus on politically sensitive issues following the evasion. If, however, a leader begins censoring information that potentially reinforces collective 
actions, we may not observe a significant increase in topic attention to sensitive issues. Censoring sensitive information also induces profit-seeking private media to focus more on apolitical but interesting news, such as sports. Although it may not be driven by explicit orders from the government, the shift in coverage may eventually divert readers' attention from sensitive issues that could facilitate mass mobilization against a leader.

I test this hypothesis by using the case of Venezuela, where President Hugo Chávez successfully removed term limits through a referendum in 2009. In particular, to show how content of media reports is affected by information control, I conduct an automated text analysis with a major opposition newspaper in Venezuela, El Nacional. Using a Structural Topic Model (STM) (Roberts, Stewart and Tingley 2019), I show that El Nacional paid less attention to some sensitive political issues, rather than more, after the term limit evasion. On the other hand, when it came to apolitical issues, such as sports and holidays, these were emphasized more.

The extant literature on presidential term limits tends to address the question of under what conditions a president evades term limits. For example, existing studies attribute the prevalence of term limit evasion to rent-seeking calculation (Baturo 2014), unrestrictive reelection rules (Negretto 2013), electoral competitiveness (McKie 2019), popularity (Corrales 2016), foreign aid (Posner and Young 2018), and youth (Posner and Young 2018). Although the determinants of term limit evasion have been well documented, there has been little discussion to date about what leaders do following a term limit evasion to keep their regimes intact. This paper fills a gap in the growing literature on term limits and serves as a starting point for comprehending the process of dictatorship after a salient democratic breakdown.

More broadly, this article addresses the question of why recent democratically elected leaders who depreciate the value of democracies try to keep their grip on media. They do so because information control is an effective way to stymie anti-government movements in the course of democratic breakdown, without using explicit repression that may backfire (Gandhi 2008). Recent studies suggest that democratic breakdowns are often perpetrated by subversion of institutions without threats of force or overt violence (Guriev and Treisman 2019, Levitsky and Ziblatt 
2018, Svolik and Chernykh 2015). In line with the growing literature, this paper contends that a leader seeking indefinite tenure through term limit evasion uses a strategy, information control to undermine the capabilities of potential dissidents to mobilize against a leader, thereby eroding democratic institutions.

This paper also contributes to the emerging literature on how a government's effort to manipulate information impedes anti-government movements that undermine regime stability. Scholars argue that leaders dissuade citizens from mobilizing against them by leveraging information control that renders people less informed (Gehlbach and Sonin 2014, Roberts 2018, Shadmehr and Bernhardt 2015), signals the regime's power (Huang 2015) and disseminates misinformation to alter public beliefs (Little 2017, Rozenas and Stukal 2019). This paper contends that leaders also have an incentive to control information when a politically salient event is expected to result in mass mobilization.

Controlling the free flow of information may not be the only way to hamper potential coordinated dissents, considering other possible tactics, such as violating physical integrity rights, that would-be dictators use to stymie anti-government actions. What this paper suggests is that information control would be one of the effective preventive measures that complement traditional repression and sheds light on how it works in the process of a term limit evasion. The remainder of the paper proceeds as follows. First, I lay out a puzzle and develop a theory, drawing upon literature on presidential term limits and information manipulation. Second, I test the main hypothesis using cross-country TSCS data. Third, using the automated text analysis, I show how the average prevalence of topics of interest changes after term limit evasion. Last, the paper concludes by discussing the possible direction of future studies.

\section{Term Limits, Evasion, and Challenges}

Since the beginning of the third wave of democratization in the 1970s, many countries with a presidential or semi-presidential system adopted term limits-constitutional restrictions on 
the maximum number of terms that the head of state, typically a president, may serve (McKie 2019). Studies on presidential term limits have focused on how term limits foster democracy by promoting leadership turnover (Ginsburg, Melton and Elkins 2011, Maltz 2007, Versteeg et al. 2020). In countries where a state leader is chosen by constituents, the incumbent benefits from an incumbent advantage, such as name recognition and popularity, so that a long-serving president can "all too easily cease to face any real danger of eviction from office, becoming functionally a life president or quasi-monarch"(Maltz 2007, 131). With a mandated leadership turnover, however, a regime is prevented from becoming an electoral authoritarian regime or a personalistic autocracy (Maltz 2007).

Term limits draw a line in the sand and make a leader's compliance easily and publicly observable (Svolik 2012, 198). Compared to other constitutional constraints, which may entail an array of interpretations, term limits are relatively simple and unambiguous. Versteeg et al. $(2020,10)$ emphasize this point, saying that "anyone who can count can establish that an incumbent's time is up, by simply comparing the number of years in each term and the number of terms allowed to the number of years and terms the current president has actually served." For this reason, term limits are often called bright-line constitutional rules (Dixon and Landau 2019, Ginsburg, Melton and Elkins 2011, Versteeg et al. 2020).

A constitution, in general, establishes a mutual expectation about how to cooperate and coordinate in particular moments (Carey 2000, Hardin 1989). Even constitutions in authoritarian regimes incorporate the distribution of power among elites and serve as a commitment device that promotes trust in the inner circles (Albertus and Menaldo 2012) based on the mutual belief that noncompliance will be punished by regime supporters. Building on this literature, I assume that term limits, as one of the "brightest" constitutional arrangements, induce citizens, in general, to form a mutual expectation that the incumbent will comply with this commitment and step down after their terms are over, regardless of competitiveness and popularity.

This expectation dissuades potential dissidents from participating in protests against a leader. And those dissidents can be either opponents or regime supporters. Opponents are those hav- 
ing grievances against a leader such that they prefer to replace the incumbent. Such grievances "create a reservoir of potential protestors" (Tucker 2007, 544) so that opponents become firstmovers whenever protests happen. Term limits, however, incentivize opponents to avoid a costly protest that could threaten their career and to wait until the incumbent steps down after their last term is over. An anti-government movement, as a collective-action, occurs when the benefits of participating in a protest outweigh the costs and the likelihood of success is relatively high (Casper and Tyson 2014, Kuran 1991, Shadmehr and Bernhardt 2011, Tucker 2007). The expectation that an unsatisfactory leader will leave the office when their term is over regardless of their popularity increases the benefits of acquiescence or decreases those of participating in protests. The former includes additional uncertainty and elite infighting generated by the withdrawal of the incumbent because of term limits, which sometimes results in the defeat of the chosen successors of a ruling clique (Baturo 2014, 212). This calculation makes it more likely that people will falsify their preferences (Kuran 1991), thereby decreasing the likelihood of successful protests. Thus, opponents under a regime with term limits are less incentivized to protest the government than those with no term limits, all else being equal. In this vein, Griner (2009) argues that "the opposition is more likely to remain a loyal opposition, rather than try to upset the system since it can envision taking power one day."

Term limits also reduce the probability of dissent from regime supporters. There are some people whose loyalty is conditional on the expectation that the incumbent will eventually step down. $^{2}$ This conditional loyalty induces aggrieved regime supporters to falsify preferences, avoid a costly protest, and support the incumbent while preparing for future leadership. For a leader, term limits allow co-optation of more people and expand the influence of a ruling coalition by sharing power vertically and horizontally. Svolik $(2012,198)$ argues that term limits encourage regime supporters to "invest their career in their own generation of leaders rather than the current political leadership." This investment enables the incumbent to co-opt multiple generations of elites. Likewise, the rotation of leaders through term limits allows horizontal

\footnotetext{
${ }^{2}$ I am not arguing all ruling supporters
} 
power-sharing among multiple factions. For example, a ruling party in Nigeria, the People's Democratic Party (PDP), stipulated an internal policy that its presidential candidates should be rotated between geographical zones after every two terms, coinciding with constitutional constraints on presidential terms (Dulani 2011). In this way, they were able to share power between two different factions of the party, one from the Muslim northern part of the country and the other from the Christian south.

Responses in a survey conducted in Africa also suggest that supporting a current regime can be conditional on the expectation of the incumbent's compliance. Using the Afrobarometer Round 6 (Afrobarometer 2016), in Figure 1, I present the relationship between a presidential approval rating or public trust in a president and public support for two-term limits. ${ }^{3}$ If public support for the incumbent does not necessarily mean that citizens also support the indefinite tenure of the incumbent, as I contend, we should not observe a positive relationship between a presidential approval rating/trust in a president and the support for the absence of term limits. Consistent with my argument, most people actually support or strongly support a two-term limit regardless of whether they approve the president's performance or trust the president. This implies that the popularity or competence of the incumbent being conditional on term limits cannot be a good indicator that dissent during and after term limit evasion will be less likely.

Although term limits can mitigate threats from potential dissidents, a leader may not be satisfied with this constitutional arrangement because the political stability rendered by term limits does not allow them to stay in the executive office, which confers considerable power and rents. Thus, leaders constrained by term limits have incentives to evade term limits (Dixon and Landau 2019). For example, President Slobodan Milosevic of Yugoslavia and, later, Serbia, con-

\footnotetext{
${ }^{3}$ The survey was conducted from 2015 to 2016 in 36 African countries. Specific questionnaires are as follows. Term limits: Which of the following statements is closest to your view? Choose Statement 1 or Statement 2. Statement $1=$ The Constitution should limit the president to serving a maximum of two terms in office. Statement $2=$ There should be no constitutional limit on how long the president can serve. Presidential Approval Rating: Do you approve or disapprove of the way the following people have performed their jobs over the past twelve months, or haven't you heard enough about them to say: President [NAME OF PRESIDENT]. Trust in President: How much do you trust each of the following, or haven't you heard enough about them to say: The President?
} 


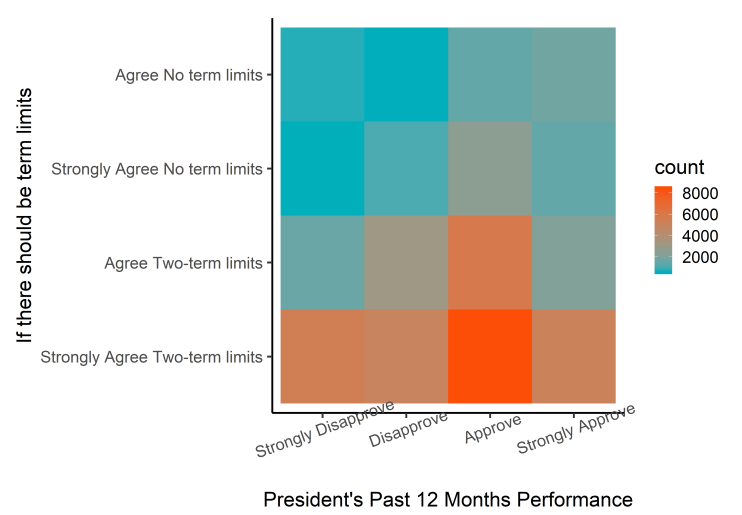

(a) Presidential Approval Rating

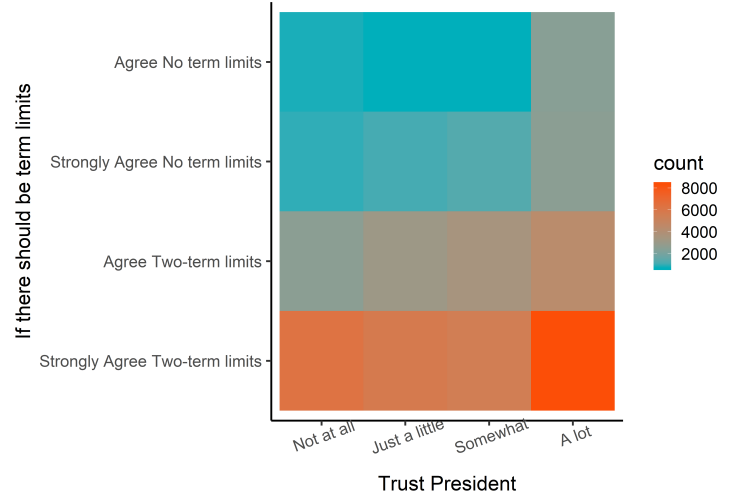

(b) Trust in President

Figure 1: Relationship Between Support for a President and Support for Term Limits

Note: Data from the Afrobarometer round 6. The survey data cover 36 countries in Africa for 2015-2016. Respondents who did not answer or refuse to answer this question are excluded.

sidered remaining in the office the only way to maximize wealth from his family business and avoid criminal charges at the international tribunal (Baturo 2014). Indeed, the findings from Versteeg et al. (2020) suggest that since 2000, nearly 25 percent of countries with presidential term limits attempts to circumvent term limits and two-thirds of those attempts succeeded. Similarly, McKie (2019) finds that nearly one-third of the presidents in their final term in the third-wave democratization regions have attempted to contravene term limits and 88 percent of them succeeded.

However, a leader seeking extended terms must overcome, to stay in the office, immediate and long-term challenges from dissidents who look forward to replacing the incumbent. In the early stage of a term limit evasion, a leader needs to deal with immediate negative responses from dissidents. The incumbent's compliance with term limits is readily observed by everyone, compared to other constitutional arrangements. As such, if a leader simply attempts to ignore the constitutional constraint without clever strategies, that noncompliance may serve as a focal point that facilitates massive anti-government movements from dissidents. The dissidents comprise not only opponents who are the first-movers from the reservoir of potential protestors but also regime supporters whose loyalty is conditional because they have invested their resources on future leaders, either in their generation or in their faction. 
Moreover, a leader who annulled a previous constitution must face long-term challenges from dissidents. In the pre-evasion world, explicit protests require a relatively high level of dissatisfaction among dissidents because acquiescence was followed by the replacement of a leader. As mentioned, this calculation makes preference falsification among potential dissidents and co-optation by a leader more prevalent. Put differently, the benefits of not participating in protests often outweigh those of the participation, which eventually entails low probability of successful protests. In contrast, in the post-evasion world, potential dissidents will no longer have this option, thereby becoming more sensitive to incompetence and dissatisfaction with the incumbent. ${ }^{4}$ In Venezuela, where President Hugo Chávez successfully evaded term limits through a referendum in 2009, leaders of dissidents claimed, right after the referendum, that "starting today, those who proposed the amendment have a greater commitment to the country because Venezuelans will be more demanding of them. The people will begin to sue their authorities like never before. There is no longer an excuse for them to kidnap a son, kill a friend." ${ }^{5}$ Thus, term limit evasions induce dissidents to be more sensitive to the wrong-doings of the incumbent, which may result in more anti-government movements.

\section{Controlling Information While Evading Term Limits}

Presidents evading term limits can expect that term limit evasion will change the calculation of dissidents, either from opponents or regime supporters, and make coordinated dissent more likely. How do leaders breaking bright-line constitutional provisions then manage the immediate and long-term threats from dissidents who want the incumbent to be replaced as soon as possible? I argue that a leader has an incentive to employ repressive strategies to prevent potential anti-government movements. More specifically, this paper focuses on one of the major

\footnotetext{
${ }^{4}$ Of course, when a leader extends term limits, people still can acquiesce until the extended term is over. However, I assume that once a leader breaks a commitment by evading term limits, people will be less likely to believe that they are committed to leaving office.

${ }^{5}$ El Nacional (2/17/2009), “"No todo es negativo, fueron muchas las victorias que conseguimos" - REACCIONES La oposición reconoció el triunfo del Sí, pero criticó el ventajismo” (Accessed via NewsBank)
} 
ways to control the mass: controlling the free flow of information. ${ }^{6}$

In the early stage of a term limit evasion, a leader is supposed to encounter immediate resentment from dissidents because the evasion serves as a focal point that signals the leader's unwillingness to comply with a constitutional commitment. However, the event itself cannot automatically become a focal point. Rather, information plays a role in providing a focal point. When information can flow freely, ${ }^{7}$ elite discourse and news regarding term limit evasion will diffuse to all citizens. Such information can then serve as a focal point by drawing public attention to the issue, assessing a leader's violations, sharing people's discontent, and legitimizing public gatherings (Daxecker 2012, Egorov, Guriev and Sonin 2009, Gohdes 2020, Lorentzen 2014). ${ }^{8}$ Furthermore, when the free flow of information is allowed, dissidents are more easily mobilized against a leader through shared information about the best course of action (e.g., through street mobilization or through institutional channels) including logistical details. As Little (2016) posits, costly collective actions against a leader will be more likely when free communication enables dissidents to readily access information about when, where, and how to protest a regime.

A term limit evasion also provides potential dissidents with a new environment in which acquiescence is no longer a viable strategy. In the post-evasion world, a leader is vulnerable to dissent more than before as citizens become impatient with wrongdoings perpetrated by the incumbent. Like the argument above, the free flow of information plays a key role in facilitating anti-government movements. Any sensitive information that reveals the incompetency of a leader is more likely to serve as a focal point than before. Moreover, free communication provides dissidents with opportunities to coordinate the best strategy for toppling the current regime. Figure 2 depicts a simple theoretical process about when information matters in a path

\footnotetext{
${ }^{6} \mathrm{I}$ am not arguing that a decrease in the freedom of expression is the 'only' way to prevent anti-government movement.

${ }^{7}$ In this paper, I use the free flow of information, freedom of expression, and free communication interchangeably.

${ }^{8}$ Analogous arguments are made in studies on how the effect of election fraud on violence is conditional on monitoring devices (Daxecker 2012, Hyde and Marinov 2014). For example, Daxecker (2012) posits that credible assessment of election manipulation, rather than the event itself, serves as a focal point for action and facilitate coordination.
} 
to protests following term limit evasion.

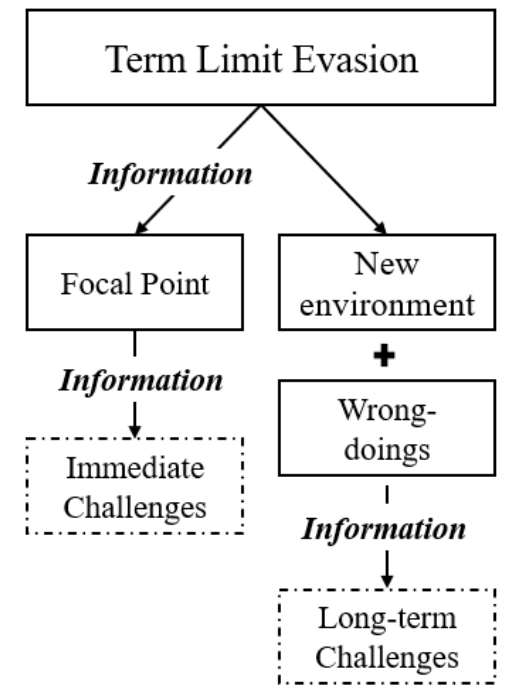

Figure 2: Theoretical process

Note: The figure depicts a simple theoretical process about how information matters in the course of protests following term limit evasion. As seen, if information is controlled, a path from term limit evasion cannot reach to immediate or long-term challenges.

The free flow of information matters following a term limit evasion. Therefore, a leader seeking indefinite tenure through term limit evasion has an incentive to control information. By controlling information, a leader can first cut a path from term limit evasion to a focal point. Then, potential dissidents have difficulty sharing discontent and legitimizing mobilization against a leader, thereby failing to draw enough people to make the anti-government movement successful. Even if a term limit evasion successfully becomes a focal point, further information control makes it difficult for dissidents to share information about the best strategy to challenge a leader.

A recent incident in Egypt provides anecdotal evidence of how, in the early stage of term limit evasion, dissidents are curtailed from sharing information that facilitates anti-government movements. In February 2019, the General Committee of the Egyptian Parliament approved a petition signed by the members of the House of Representatives to amend some constitutional provisions, including a clause that would allow Abdel Fattah El-Sisi, the president who was sup- 
posed to leave the office after serving his current term, to seek one more term in the office. ${ }^{9}$ In response to this proposed change, a number of dissidents, including opposition parties and elites, organized a group called "Union to Defend the Constitution" and planned to oppose the change by coordinating peaceful but effective strategies of collective action. The union claimed that it would employ three main strategies to challenge the constitutional amendment: organizing a popular campaign to collect signatures against the amendments that would also raise awareness of the dangers of the amendments, creating its own media platform, and finding a way to challenge the amendments legally. ${ }^{10}$ Although the campaign against the proposed amendments, titled "Void," gathered nearly 60,000 signatures within hours of its launch, the government immediately blocked its website. Moreover, the government subsequently banned access to nearly 34,000 internet domains that promoted the opposition campaign. ${ }^{11}$ This information control effectively stymied potential collective dissent against the leader and enabled President Sisi to readily win in a referendum.

In the longer-term, a leader has an incentive to maintain information control to conceal wrongdoings, which could otherwise easily induce dissidents to resent the government. A quintessential example is found in Venezuela, after President Chávez's term limit evasion in 2009, when the court made reporting violent images in any publication illegal. This ruling was made after $E l$ Nacional, one of the major opposition newspapers, posted a photograph of bloody bodies piled up at an overcrowded Caracas morgue. The newspaper attempted to raise concern about the increasing rate of violent crime, perhaps as a signal of the instability of Chávez regime. ${ }^{12}$ Similarly, in Azerbaijan, several press-freedom-related constitutional arrangements were amended in the 2009 referendum, simultaneously with the removal of presidential term limits. Among them was to restrict people from following, filming, photographing and recording anyone with-

\footnotetext{
${ }^{9}$ George Sadek. "Egypt: New Constitutional Amendments Proposed.” Library of Congress (February 13, 2019). https://bit.ly/2YtmgI6.

${ }^{10}$ Mada Masr. “' 'Union to Defend the Constitution' brings opposition forces together to reject constitutional amendments.” (February 7, 2019). https://bit.ly/2NuIYcA.

${ }^{11}$ Netblocks. "Egypt filters 34,000 domains in bid to block opposition campaign platform.” (April 15, 2019). https://bit.ly/2B9p2t1

${ }^{12}$ Rory Carroll. "Venezuela ban on violent images fuels censorship row." (August 18, 2010). https://bit.ly/ 3g2kGTD
} 
out his or her knowledge, or despite his of her disapproval. For journalists, this was considered curtailing their professional activities, especially those targeting the government. ${ }^{13}$

Eventually, leaders evading term limits can kill two birds (immediate and long-term challenges) with one stone (information control). Therefore, I first hypothesize that a leader evading term limits will constrain freedom of expression to impede the probability of group challenges from dissidents. Since a leader's true intention is rarely observable, I operationalize it as a decrease in freedom of expression after the initiation of a term limit evasion.

Hypothesis 1: The freedom of expression will decrease after the initiation of a term limit evasion.

Although all leaders seeking indefinite terms through a term limit evasion may have an incentive to restrict freedom of expression to prevent coordinated dissent against them, enacting such a preemptive strategy is a different story. Especially, when a country has well-developed democratic institutions, curtailing the rights of people in the absence of an actual dissent will backfire. This expectation builds on a study by Ritter and Conrad (2016) that shows empirically that democratic governments are more likely to engage in reactive forms of repression, rather than preventive repression. The authors suggest that unlike authoritarian governments with fewer constraints, constraining institutions in democracies increase costs for the government to employ preventive repression as the public who holds political authorities accountable will backlash against attacks on citizens without clear cause (Ritter and Conrad 2016, 92).

Moreover, leaders evading term limits in democracies have limited tools to constrain information because media outlets, one of the crucial information sources, are more likely to be private and market-oriented than those in autocracies. To curtail profit-driven private media outlets from reporting sensitive information, a leader must compensate for the loss of potential profits from advertising, which increase with the size of the advertising market. What matters is that the expansion of the advertising market itself is not readily controllable as it is influenced in part by such external factors as the development of media technology (Gehlbach and Sonin

\footnotetext{
${ }^{13}$ https://www.refworld.org/docid/49c745adle.html
} 
2014). As such, unlike leaders in autocracies where most media are directly or indirectly controlled by the government, leaders in democracies have limited resources to control the free flow of information to prevent coordinated dissents. Therefore, I hypothesize that restricting the freedom of expression by a leader evading in term limits will be more salient in autocracies where leaders are less likely to be constrained.

Hypothesis 2: A decrease in the freedom of expression after the initiation of a term limit evasion will be more salient in autocracies than in democracies.

If information control following a term limit evasion works, we should see the evidence of information control in the content of media reports. The literature on authoritarianism has posited that leaders limit access to sensitive information that may facilitate an anti-government movement. This may take the form of direct censorship (King, Pan and Roberts 2013, Qin, Strömberg and Wu 2017, Roberts 2018, Shadmehr and Bernhardt 2015) and/or distraction of public attention with a deluge of signal-jamming information (De Angelis and Vecchiato 2018, Roberts 2018). I hypothesize that a leader evading term limits will control information using both censorship and distraction.

To investigate how media content is affected by a leader's efforts to control information, this paper focuses on changes in the prevalence of certain content in private media rather than state-owned media. This is because the latter serves as government mouthpiece that always filters sensitive information, so that it may not be possible to observe differences in sensitive information before and after term limit evasion. Private media profits, on the other hand, derive from advertising revenues from private companies or subscription fees from readers and, thus, they have an incentive to focus on the most salient political issues that everyone will be interested in. Term limit evasion, in this sense, is one of the most salient and crucial political events that private media would love to cover. Thus, if there were no external pressure curtailing the freedom of expression, term limit evasion would be followed by an increase in media reports that deal with politically sensitive issues, especially those relevant to term limit evasion. 
If, however, a leader begins censoring sensitive information that could reinforce collective action, as I hypothesize, we may not observe significant changes of topic attention about political issues, even after term limit evasion.

Censorship of threatening information induces private media to focus more on apolitical news. As noted, to increase subscriptions private media have an incentive to focus on salient issues with broad appeal. However, external pressure to censor such information induces those media to seek alternative ways to fill empty spaces and time to interest readers. I hypothesize that manipulated media will therefore be more likely to focus on apolitical but interesting news such as sports. Although focusing on apolitical issues may not be driven by explicit orders from the government, it eventually diverts readers' attention away from sensitive issues that could facilitate mass mobilization against a leader.

Hypothesis 3: There will be an increase in distracting and non-political information in opposition media after the initiation of term limit evasion. In contrast, there will not be an increase in sensitive political topics.

\section{Difference-in-Differences with Matching for TSCS}

\subsection{Operationalization}

To test Hypothesis 1 and 2, I use time-series cross-sectional (TSCS) data from 1960 to 2010 on countries with a presidency or semi-presidency where term limits exist when a leader enters the office. The hypotheses hold that the freedom of expression will decrease after the initiation of term limit evasion. Since I define term limit evasion as a process of successful contravention of term limits, this hypothesis can be precisely operationalized as freedom of expression decreasing after the first announcement or proposal to circumvent term limits. Obviously, using the "daily-level" cross-country data on freedom of expression as a dependent variable would be the best way to investigate the timing of information control. Unfortunately, however, researchers do not have the daily-level data at their disposal yet, and only year-level data are avail- 
able. Readers are advised to acknowledge this limitation and this paper attempts to provide the best possible interpretations of results within the limitations posed by the data.

I modify a circumvention of the term limit dataset by Baturo (2014) based on the following criteria. First, a national leader of a country-year must be a unitary actor who is an effective national executive directly or indirectly elected by constituents. I exclude a country-year in which a term-limited leader who is called president is ceremonial. The data for effective leaders are extracted from the Archigos V.4.1. (Goemans, Gleditsch and Chiozza 2009). Second, all national leaders enter the office with term limits, and term limit evasion can happen only when a leader is constrained or understood to be constrained by term limits in the first place. This condition excludes a country-year in which national leaders are not constrained by term limits. Examples are prime ministers, kings in monarchies, general secretaries of one-party states, and presidents without term limits.

Scholars have documented several modes of term limit evasion (see Baturo 2014, Ginsburg, Melton and Elkins 2011, Versteeg et al. 2020). First, some leaders in their last term amended the existing constitution to seek one more term. Second, some presidents reset their term and start a new countdown by promulgating a new constitution and annulling the constraints of a previous constitution. Third, a few leaders eliminate term limits. Last, some scholars (e.g. Baturo 2014) also characterize a more subtle way of extending terms as term limit evasion, such as when a president technically steps down from office after the last term, but assumes a different office and strengthens that office while diminishing the power of the president. The quintessential example is Vladimir Putin of Russia in 2008. After completing his final term in 2008, he assumed the position of prime minister and put Dmitry Medvedev in office as a "placeholder president" (Versteeg et al. 2020). Following the general definition of term limit evasion, I do not include this case as term limit evasion in my TSCS analysis. However, including this case in data does not change the result.

I use a Freedom of Expression and Alternative Sources of Information index from V-Dem to proxy freedom of expression. This index uses a Bayesian factor analysis that incorporates mul- 
tiple indices that measure the degree to which the government respects media freedom, the freedom of ordinary people to discuss politics, and freedom of academic and cultural expression. The scale of this measure is from 0 (lowest) to 1 (highest).

The independent variable, Term Limit Evasion, is coded as 1 in the first year in which the incumbent leader successfully ${ }^{14}$ circumvents constitutional constraints by extending or repealing term limits and every subsequent year under the same leadership, and 0 otherwise. ${ }^{15}$ Here, term limit evasion is considered to have occurred when the incumbent leader explicitly amended a constitution or promulgated a new constitution to extend or remove term limits. Based on the theoretical concept of term limit evasion, it should be coded based on the first announcement or proposal of circumventing term limits. Put differently, the coding is supposed to be based on the initial public recognition of the government's attempt, not on the event through which term limits are officially annulled. However, due to the limitation of information about the date of the first proposal, this is rarely possible. ${ }^{16}$ Despite this limitation, I assume that focusing on the event is a good proxy because, based on the best available data, the official proposal or announcement tended to occur in the year of the official event, such as a referendum or parliamentary decision, or at the end of the previous year. ${ }^{17}$

Also, this coding makes the first year of term limit evasion $(t)$ encompass a few days before term limit evasion evasion. That is, $t$ of a treatment period may have some non-treatment period as well. Later in the estimation, I show that the estimated change of the freedom of expression at $t+1$ is indeed bigger than $t$ although estimated change at $t$ significantly differs from $t-1$.

Hypothesis 2 posits that the degree to which freedom of expression decreases following a term limit evasion is conditional on the level of existing democratic constraints. As a moderator, I use a dichotomous indicator of democracy based on the Polity IV score at $t-1$. The indicator

\footnotetext{
${ }^{14}$ It means that I exclude a few failed term limit evasion attempts.

${ }^{15}$ The coding of a ruler is decided based on who remains in office on July lst of that year.

${ }^{16}$ Unlike official events, first public announcement or proposal should be found in local or international media reports. However, not all proposals were clearly reported by media.

${ }^{17}$ Examples are Azerbaijan (12/19/2008), Bolivia (12/18/2006), Dominican Republic (12/24/2001), Cameroon (12/31/2007), and Niger (12/22/2008).
} 
is coded as a democracy if Polity is equal to or greater than 5. I intentionally avoid using the score at $t$ because this indicator is highly reliant on the degree of constraints on the executive, which is relevant to term limits.

To account for potential pre-treatment covariates, I include a battery of covariates in the estimation process. ${ }^{18}$ First, I control for level of electoral democracy before term limit evasion. It seems highly plausible that authoritarian countries and emerging democracies are more likely to suffer the breakdown of political institutions through the actions of a leader. The fact that term limit evasion is more prevalent in Latin America and Africa than Europe underscores this possibility. Moreover, democracies are argued to be less prone to repression (Davenport 2007, Poe, Tate and Keith 1999). I use a lexical index of electoral democracy (LIED) developed by Skaaning, Gerring and Bartusevičius (2015), which solely focuses on electoral democracy. This index provides an ordinal scale of whether elections are sufficiently free based on several conditions. The identifying conditions are elections for the legislature, elections for the national executive, multiparty competition, male suffrage, female suffrage, and the quality of elections.

Second, natural resources are included in covariates. Baturo (2014) suggests that leaders with many resource endowments have more incentives to evade term limits to keep spoils of office. Also, the resource curse literature has posited that abundant natural resources contribute to the personalization of the regime (Fails 2019), which is then prone to repression, such as information constraints (Frantz et al. 2020). To control for this confounder, I use data for a country's value of oil and gas, collected by Ross and Mahdavi (2015), as a proxy of natural resources. ${ }^{19}$

Third, I include a binary indicator of whether a country-year sees any domestic or international armed conflict. External threats from armed opponents may induce a leader to extend his term, with the rationale that the country needs a stable regime to overcome external threats. The data for armed conflicts are taken from UCDP/PRIO Armed Conflict Dataset, version 19.1

\footnotetext{
${ }^{18}$ More specifically, I control for the history of pre-treatment covariates, as well as that of treatment conditions. This is different from how covariates are used in a traditional TSCS regression. More details are provided in the next section.

${ }^{19}$ To transform the non-linearity of oil data with many 0s, I use the Inverse Hyperbolic Sine (IHS) transformation.
} 
(Gleditsch et al. 2002, Pettersson, Högbladh and Öberg 2019). Last, I include logged GDP per capita and GDP growth in the estimation model to capture the effect of economic development. $^{20}$

\subsection{Estimation}

The theoretical expectation suggests that we ought to observe a significant decrease in freedom of expression from a year of term limit evasion $t$, as compared to that in a counterfactual from $t$ where no term limit evasion occurs, all else being equal. However, that term limit evasions are not randomly assigned but endogenous to a leader's decision makes estimation difficult because I need to estimate a treatment effect under the assumption of strict or sequential exogeneity, which is difficult, as unobserved confounders can never be controlled. Without a clever estimation strategy, it is difficult to discern whether a term limit evasion provides with a leader evading term limits a critical juncture that incentivizes them to constrain freedom of expression, or it simply reflects a general trend of authoritarianism such that controlling information has already been conducted by such a leader.

Scholars have commonly used linear two-way fixed effects regression to estimate generalized difference-in-differences (DID) when the treatment is dichotomous. However, recent scholarship questions whether the linear model properly generates a counterfactual within repeated observations (e.g. Borusyak and Jaravel 2017, Goodman-Bacon 2018, Imai and Kim 2020, Imai, Kim and Wang 2020, Kropko and Kubinec 2020). For example, Imai, Kim and Wang (2020, 7) contends that "In addition to the fact that the linearity assumption may be too stringent, it is also difficult to understand how these models use observed data to estimate relevant counterfactual quantities.” Moreover, they point out that generalized DID can not be simply applied to linear two-way fixed effects regression when treatment conditions within a unit constantly change. Since a country in my data can go in and out of the treatment condition-that is, a country can experience multiple term limit evasions-a conventional linear model with two-

\footnotetext{
${ }^{20}$ These data are extracted from the Maddison Project by Bolt et al. (2018)
} 
way fixed effects may not properly estimate treatment effects of interest.

To address this issue and improve the quality of estimation, I benefit from the nature of TSCS data, utilizing the difference-in-differences (DID) estimator with a matching method that allows for matching the history of treatments and a similar level of covariates (Imai, Kim and Wang 2020). ${ }^{21}$ Matching, in general, improves the validity of causal inference by comparing treated and control observations that share similar characteristics (Ho et al. 2007). In line with this concept, Imai, Kim and Wang (2020) proposes a matching method that incorporates the characteristics of TSCS data in which the timing of receiving treatment varies across units. To elaborate, it estimates the average treatment effect for the treated (ATT) by matching each treated observation with a group of control observations that shares the history of treatments up to the pre-specified time period. This group of control observations are called a "matched set." The matched sets are further refined by regular matching methods, such as the Mahalanobis distance and propensity score weighting, to account for pre-treatment confounders and outcome histories. Last, a possible unobserved time trend is adjusted by the application of a DID estimator. Compared to the linear model with a stringent linearity assumption, this model is nonparametric with less model dependence. Moreover, since this method estimates ATT within matched sets, it is appropriate for my unbalanced TSCS dataset. ${ }^{22}$

Figure 3 depicts the example of this procedure in my analysis. Each treated unit is first matched with a group of control units-the matched set-sharing the same history of treatment, which is term limit evasion, up to $t-L$. Note that $X_{i, t-1}$ always has to be 0 to conduct the DID estimator. Although $L$ can be selected among any non-negative integer, Imai, Kim and Wang $(2020,11)$ suggest that a relatively large $L$ can "increase the credibility of limited carryover effect and the parallel trend assumptions." As such, I choose $L=4$ to guarantee enough credibility. After the initial matching, the matched sets are refined by selecting some control groups up to $J$, based on similar confounders and outcome histories. In the analysis, I use propensity

\footnotetext{
${ }^{21}$ I use the open-source statistical software, PanelMatch: https://github.com/insongkim/PanelMatch

${ }^{22}$ Other generalized difference-in-differences methods, such as Bacon Decomposition, require a perfectly balanced panel.
} 
score weighting refinement, which provides the best mean covariate balance. ${ }^{23}$ For the specification of matching, I include four years of lag for pre-treatment covariates and outcomes, in accordance with $L$. In Figure 3, I show, as an example, that three blue-colored units are eventually selected as a control group because they share similar characteristics with a treatment unit. The weighting refinement that I use automatically selects $J$ that best fits the model.

\begin{tabular}{|c|c|c|c|c|c|c|c|c|}
\hline \multicolumn{9}{|c|}{ Pre-specified $L=4$} \\
\hline \multirow{6}{*}{$\mathrm{J}=3 \multimap$} & & $\begin{array}{c}\text { Weight } \\
\text { by refinement }\end{array}$ & Evasion $_{t-4}$ & Evasion $_{t-3}$ & Evasion $_{t-2}$ & Evasion $_{t-1}$ & Evasion $_{t}$ & \multirow{6}{*}{$\begin{array}{l}\text { Treated: } \boldsymbol{Y}_{\mathrm{i}, \mathrm{t}-1} \rightarrow \boldsymbol{Y}_{\mathrm{i}, \mathrm{t}(+F)} \\
\qquad \text { Diff-in-diffs } \\
\text { Weighted average of } \\
\text { Control: } \boldsymbol{Y}_{\mathrm{i}, \mathrm{t}-1} \rightarrow \boldsymbol{Y}_{\mathrm{i}, \mathrm{t}(+F)}\end{array}$} \\
\hline & Country $_{A}$ & & 1 & 0 & 0 & 0 & 1 & \\
\hline & Country $_{B}$ & $w_{b}$ & 1 & 0 & 0 & 0 & 0 & \\
\hline & Country $y_{C}$ & $w_{c}$ & 1 & 0 & 0 & 0 & 0 & \\
\hline & Country $_{D}$ & $w_{d}$ & 1 & 0 & 0 & 0 & 0 & \\
\hline & $\begin{array}{l}. \\
. \\
.\end{array}$ & $\sum w=1$ & 1 & 0 & 0 & 0 & 0 & \\
\hline
\end{tabular}

Figure 3: Example of a Treated Unit and its Matched Set

Note: A red-colored unit refers to a treated group and blue-colored units depict a matched set. 1 indicates that term limit evasion happens in a country-year and 0 otherwise. $L$ indicates the number of lags a researcher allows for treatment matching, and $J$ refers to the number of control units a researcher allows for the refined matching with previous outcomes and confounders. Refinement methods that pre-specify $J$, such as Mahalanobis matching, place an equal weight $\left(w_{b}=w_{c}=w_{d}\right)$ to each observation in the matched set. On the other hand, other refinement methods, such as propensity weighting, that automatically select $J$ do not place an equal weight to each observation. Eventually, the sum of all weights must be equal to $1\left(\sum w=1\right)$.

Last, adopting the difference-in-differences (DID) design, the estimator calculates the following average treatment effect of term limit evasion for the treated (ATT) :

$$
\delta(F, L)=\mathbb{E}[\underbrace{Y_{i, t+F}\left(X_{i t}=1, X_{i, t-1}=0,\left\{X_{i, t-l}\right\}_{l=2}^{L}\right)}_{\text {potential outcome under term limit evasion }}-\underbrace{Y_{i, t+F}\left(X_{i t}=0, X_{i, t-1}=0,\left\{X_{i, t-l}\right\}_{l=2}^{L}\right)}_{\text {potential outcome without term limit evasion }}]
$$

where those each treatment group is a country-year experiencing term limit evasion at $t=1$ (i.e., $X_{i, t-1}=0, X_{i t}=1$ ), while sharing the same treatment history with a matched set until $L$ (i.e., $\left\{X_{i, t-l}\right\}_{l=2}^{L}$ ). $F$ is the number of leads representing the outcome of interest measured at $F$

\footnotetext{
${ }^{23}$ The authors of this method suggest that .2 is a helpful threshold value as a rule of thumb. When using the propensity score weighting, all covariates meet this criteria. The grey lines in Figure 6 illustrate this trend.
} 
time periods after term limit evasion occurs. For the estimation, I use the period of five years after term limit evasion (i.e., $F=0,1,2,3,4$ ), which then enables me to estimate long-term effects of term limit evasion as well as the immediate effect. This identification strategy assumes that there exists a parallel trend of potential outcomes between a pre-evasion year $t-1$ and the term limit evasion year $t+F$, after conditioning on the treatment history, lagged outcomes, and covariate histories.

In terms of estimation, the potential outcome without term limit evasion is estimated using the weighted average of the control units in the refined matched set. Subsequently, the DID estimates for each treated observation are computed and averaged across all treated observations. In addition, I use a 1000-block-bootstrap to compute conventional standard errors. Thus, the matching for TSCS allows for calculating how the degree of the freedom of expression changes from the initiation of term limit evasion at $t$ in subsequent years as compared to control groups sharing the same histories of treatments and similar confounders.

\subsection{Testing Hypothesis 1}

Table 1 presents the matching estimates of the effect of term limit evasion on freedom of expression for varying $F$. I run separate models for each value of $F$ because each model has the different number of treated groups. ${ }^{24}$ Across all models, the results show that freedom of expression decreases significantly in the year of a term limit evasion $(t)$, which proxies the initiation of a term limit evasion, and subsequent years after the evasion $(t+1-t+F)$. As previously mentioned, due to some nontreatment periods at $t$, the estimated change after $t$ is bigger. Substantively, based on Model 4, which is also depicted in Figure 4, a country-year experiences a 2.7 percent decrease in freedom of expression in the year of term limit evasion. Moreover, its negative relationship becomes severe over time, and a country-year experiences a nearly 7 percent decline in the freedom of expression at $t+4$. This result supports Hypothesis 1 , indicating

\footnotetext{
${ }^{24}$ This is because treatment groups are being excluded when F gets bigger. For example, when a leader evading term limits survives until $t+1$, they are included in Model $1(\mathrm{~F}=1)$, but excluded in other models, where $F=n, n>1$.
} 
Table 1: Matching Estimates of the Effect of Treatment over Time

\begin{tabular}{lcccc}
\hline \hline Time & Model 1 & Model 2 & Model 3 & Model 4 \\
& $\mathrm{F}=1$ & $\mathrm{~F}=2$ & $\mathrm{~F}=3$ & $\mathrm{~F}=4$ \\
\hline$t$ & -0.023 & -0.025 & -0.026 & -0.027 \\
& $(0.010)$ & $(0.010)$ & $(0.011)$ & $(0.012)$ \\
$t+1$ & -0.040 & -0.044 & -0.046 & -0.050 \\
& $(0.013)$ & $(0.014)$ & $(0.016)$ & $(0.016)$ \\
$t+2$ & & -0.047 & -0.051 & -0.056 \\
& & $(0.015)$ & $(0.018)$ & $(0.018)$ \\
$t+3$ & & & -0.057 & -0.062 \\
& & & $(0.019)$ & $(0.020)$ \\
$t+4$ & & & & -0.070 \\
& & & & $(0.022)$ \\
\hline $\mathrm{n}$ (Obs.) & 2,299 & 2,299 & 2,299 & 2,299 \\
$\mathrm{n}$ (Treated) & 48 & 44 & 39 & 38 \\
Avg(Matched Set) & 38.83 & 36.89 & 34.18 & 33.37 \\
\hline \hline
\end{tabular}

Note: Bootstrapped standard errors are reported in parentheses. Avg(Matched Set) refers to an average number of a matched set, or control group, assigned to each treated unit. Note that the average number of matched sets decreases as the number of leads in a model, $F$, increases because treatment groups are being excluded when $\mathrm{F}$ gets bigger. For example, when a leader evading term limits survives until $t+1$, they are included in Model 1, but excluded in other models, where $F=n, n>1$.

the freedom of expression significantly decreases after the initiation of a term limit evasion.

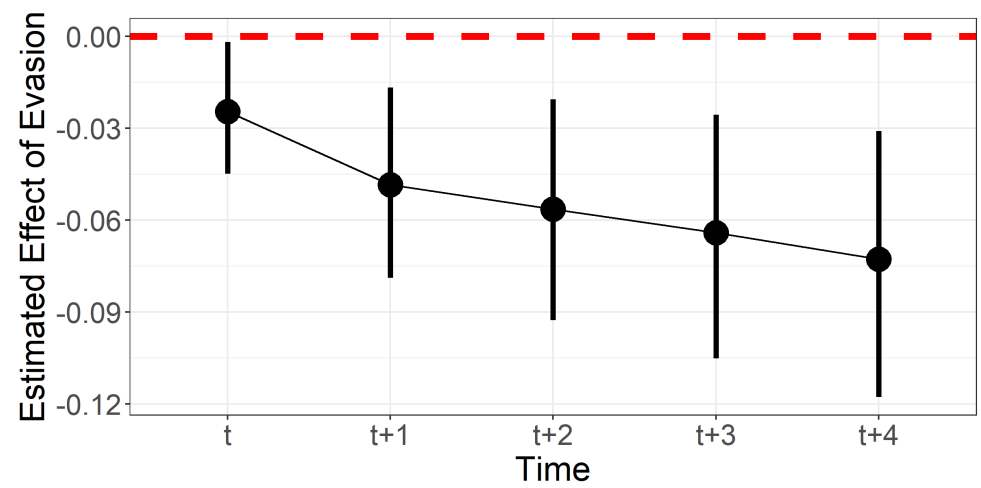

Figure 4: Matching Estimates of the Effect of Treatment over Time 


\subsection{Testing Hypothesis 2}

I contend in Hypothesis 2 that a decrease in freedom of expression after the initiation of a term limit evasion will be more salient in autocracies than in democracies. In other words, the decrease in the freedom of expression is conditional on a regime type. Although most countries experiencing term limit evasion were under autocracy (Polity $t_{t-1}<5$ ), some countries with democratic institutions also experienced term limit evasions. To test this conditionality, I employ the modification of matching for TSCS, in which I find the matched set as usual, but within a set of a treated unit and the matched controls, I focus on the treated observations that take a specific value of the moderator. Estimates are then computed using all the control observations. ${ }^{25}$ Figure 5 illustrates the result based on Model $4 .^{26}$ As I hypothesize, the decrease in freedom of expression is more salient in autocracies than in democracies despite similar decreasing patterns across all regime types.

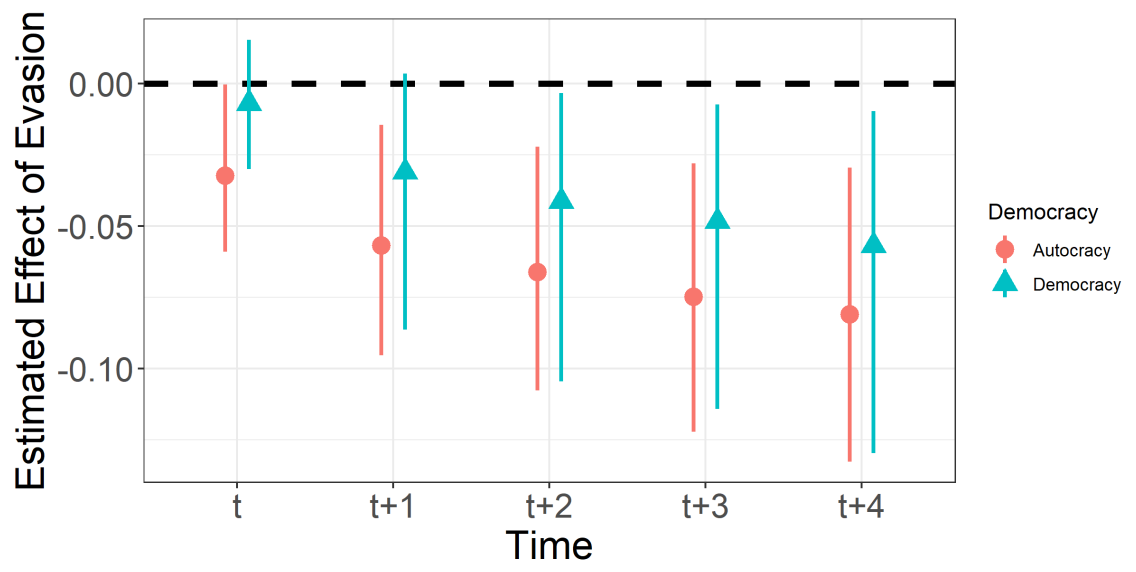

Figure 5: Matching Estimates Conditional on Democracy

\subsection{Parallel Trend Assumption}

DID estimator assumes that estimates are unbiased when the parallel trend assumption holds. Figure 6 illustrates a standardized mean difference of each covariate between a treated observa-

\footnotetext{
${ }^{25}$ Specifically, I take advantage of moderating.variable function in the PanelMatch package.

${ }^{26}$ Results from other models are consistent with this finding and reported in the appendix.
} 
tion and its matched set at each pre-treatment period for the four main models. ${ }^{27}$ Specifically, each black line represents the standardized mean difference of the lagged outcome variable over multiple pre-treatment periods. As can be observed, the lines for all models are almost flat, which implies that the outcome variable has a parallel trend in pre-treatment periods.

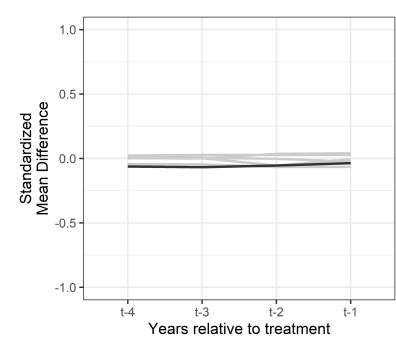

(a) Model $1(\mathrm{~F}=1)$

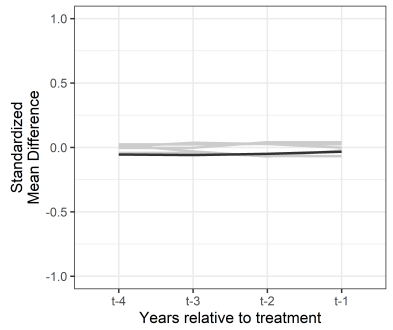

(b) Model $2(\mathrm{~F}=2)$

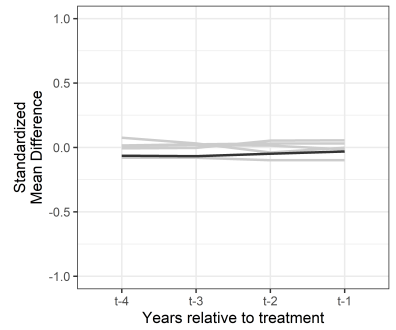

(c) Model $3(\mathrm{~F}=3)$

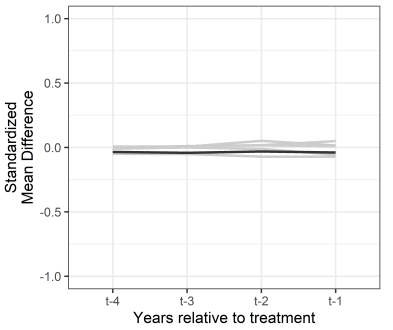

(d) Model $4(\mathrm{~F}=4)$

Figure 6: Standardized Mean Difference over the Pre-Treatment Time Period of Four Years

\section{How Does a Leader Control information?: The Case of Venezuela}

The TSCS analysis shows that there is a statistically significant decrease in freedom of expression in the year of term limit evasion and in subsequent years. How exactly,then, does a leader control information? Hypothesis 3 predicts that there will be an increase in distracting and nonpolitical information in opposition media after the initiation of a term limit evasion. In contrast, there will not be an increase in sensitive political topics. In this section, I test this hypothesis, using the case of Venezuela, where President Hugo Chávez removed presidential term limits via referendum in 2009, after he failed to overturn term limits in an earlier referendum in 2007. Specifically, I analyze the patterns of texts used in El Nacional, the major opposition newspaper in Venezuela.

\footnotetext{
${ }^{27}$ The mean difference is standardized by "the standard deviation of each covariate across all treated observations in the data so that the mean difference is measured in terms of standard deviation units" (Imai, Kim and Wang 2020, 16).
} 


\subsection{Automated Text Analysis of El Nacional}

The primary corpus of interest is El Nacional, collected from Lexis Nexis and NewsBank. It comprises 49,590 articles from September 22, 2006, to July $12,2011 .{ }^{28}$ Before conducting any quantitative analysis of text as data, I make raw texts less complex by removing uninformative texts in a way that does not harm substantive interpretation. This process is called "preprocessing," and researchers are advised to go through this process before the main analysis (Grimmer and Stewart 2013). In keeping with the suggestion of Denny and Spirling (2018), I remove punctuation, special characters, and numbers; lowercase all letters in all words; stem words, that is, reduce a word to its most fundamental form; remove conventional Spanish stopwords; ${ }^{29}$ and remove infrequently (less than 1 percent) used terms.

The purpose of the text analysis is to examine how the prevalence of reports related to sensitive information that may facilitate anti-government movements and distracting apolitical information changes after the referendum. To do so, I estimate a probabilistic model of word occurrences in newspaper articles, using a Structural Topic Model (STM) (Roberts, Stewart and Tingley 2019). Like Latent Dirichlet Allocation (LDA), a commonly used unsupervised topic model, STM defines a document as a mixture of multiple topics, "a mixture over words where each word has a probability of belonging to a topic" (Roberts, Stewart and Tingley 2019, 2). Specifically, I am interested in how much a document, on average, is associated with a topic, hence topic prevalence. For example, a newspaper article about term limit evasion can be a mixture of topics: 30 percent on Referendum, 20 percent on the Constitution, 20 percent on the President and 20 percent on Protest. Unlike LDA, the STM allows for the inclusion of covariates that define the prior distribution of the topic prevalence. Since I assume that a salient political event such as a referendum changes a prior distribution of topics in reports, I include date of

\footnotetext{
${ }^{28}$ The primary source of data, Lexis Nexis, provides El Nacional articles from September 22, 2006, 877 days before the second referendum in 2009. To balance the corpus I collect articles through July 12, 2011, 877 days after the referendum.

${ }^{29}$ I first remove conventional Spanish stopwords, using the Snowball package in R and then run several preliminary models to see if meaningless words still constitute a topic. After removing those words, if any, I run a final model.
} 
publication $^{30}$ as a key covariate in the model. In the main analysis, I set the number of topics to $K=50$ after conducting multiple models with a variety of $K$. Among 50 topics, six topics related to sensitive and distracting issues stand out, as presented in Table 2.

Table 2: STM Results with FREX words (in English)

\begin{tabular}{lll}
\hline Topic \# & Topic Label & Frequent and Exclusive (FREX) words \\
\hline Sensitive Topics & & \\
22 & Referendum & reform, constitution, law, proposal, referendum \\
\hline 33 & Crime and Prosecution & prosecution, attorney, judicial, criminal, sentence \\
\hline 46 & President Chávez & Chavez, Hugo, president, presidency, chief \\
\hline Distracting Topics & & \\
10 & Sports: Baseball & manager, baseball, player, league, pitcher, \\
\hline 48 & Sports: Soccer & soccer, tournament, player, national team, goal \\
\hline 49 & Holidays & Christmas, travel, return, permission, vacation \\
\hline
\end{tabular}

Hypothesis 3 predicts an increase in information control after the initiation of a term limit evasion. That is, after term limit evasion, there will be no increase in sensitive information while there will be an increase in distracting information. In the case of Venezuela, there will be some evidence of information control during and after the second referendum in 2009, which successfully removed term limits. On the other hand, If an attempt to evade term limits fails so that the mutual expectation does not change, a leader has no incentive to place more efforts on controlling information to hamper mobilization. Thus, there should be no evidence of increased information control after the first referendum, which failed.

\subsection{Results}

Figure 7 presents how the average prevalence of sensitive topics changes over time. There are two major sensitive topics that directly relate to term limit evasion: Referendum and President Chávez. Also, there is one sensitive topic that may serve as a focal point in the post-evasion period: Crime and Prosecution. The first thing to note is that the prevalence of topics related to

\footnotetext{
${ }^{30}$ Following the suggestion of Roberts, Stewart and Tingley (2019), I use a b-spline transformation.
} 
the referendum and President Chávez decreases after the second referendum. Given that term limit evasion is one of the most salient and crucial political events, private media seeking more public attention might be willing to focus on this issue and the president who benefits from this event. Moreover, considering that El Nacional was a leading opposition media outlet that criticized the referendum and asked people to vote "no", ${ }^{31}$ it could be expected keep on reporting negative aspects of term limit evasion and condemning Chávez after the second referendum if it were not pressured by the government. However, as observed in Figure 7(a) and (b), attention to these topics decreased, consistent with Hypothesis 2.

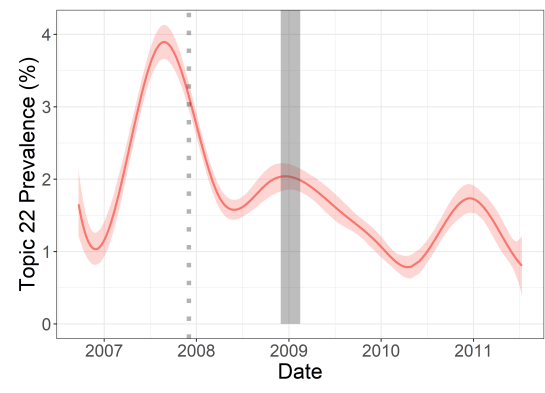

(a) Referendum

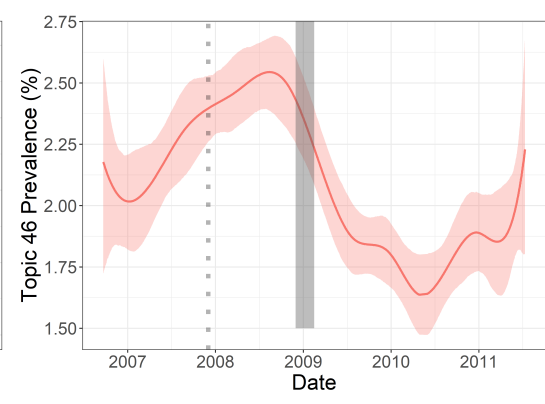

(b) President Chávez

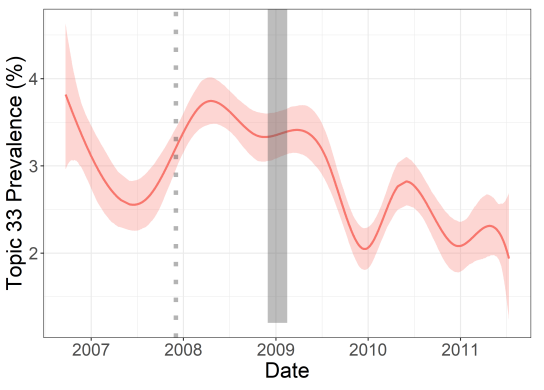

(c) Prosecution and Crimes

Figure 7: The change of average topic prevalence over time: Sensitive Topics

Note: The dotted line indicates the date of the first (failed) referendum (12/02/2007), and the gray area indicates the term limit evasion (11/30/2008 - 02/15/2009).

Figure 7 (c) shows that there is a decreasing trend of the prevalence of topics related to prosecution and crimes. The main argument holds that a leader has an incentive to keep their control of information after term limit evasion because dissidents are now more sensitive to issues that evince wrongdoings or the incompetency of the incumbent. This is why dissidents in Venezuela after the referendum claimed that "the people will begin to sue their authorities like never before." ${ }^{32}$ As expected, Figure 7 (c) suggests that the private media are constrained from focusing on a topic that alludes to the instability of a regime and makes constituents resent the government. It is not that the number of actual crimes in Venezuela after the term limit

\footnotetext{
${ }^{31}$ El Nacional kept reporting '2D Movement,' which encouraged people to vote "No" in the referendum. One exemplary title is "If the Yes wins, Venezuela would have a mummy government - REFLECTION 2D Movement says No to indefinite reelection that ends democratic freedoms." (2/9/2009)

${ }^{32}$ Refer to the footnote 3
} 
evasion decreased.; in fact, there is a plethora of evidence that domestic crimes and violence were prevalent after the referendum.

Figure 8 shows the change in the average prevalence of topics related to distractions such as sports and holidays, whose topic prevalence seems to increase over time after the second referendum. Among the prevalent topics, those related to baseball stand out. Before the second referendum, the prevalence of baseball topics declined over time, arguably because there were many crucial political events, such as a referendum and a local election, so that El Nacional had an incentive to devote its limited space to reporting those salient issues. However, after the term limit evasion in the second referendum, there is a dramatic surge of baseball topics (an approximately 4 percent increase).

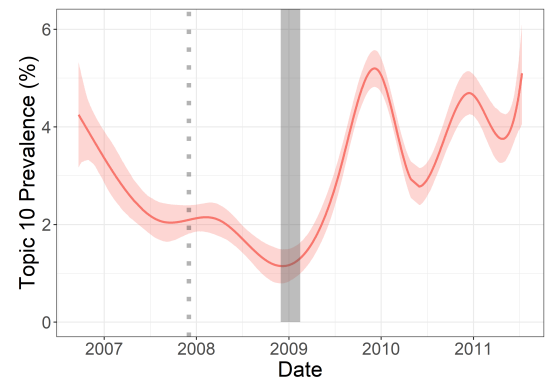

(a) Sports: Baseball

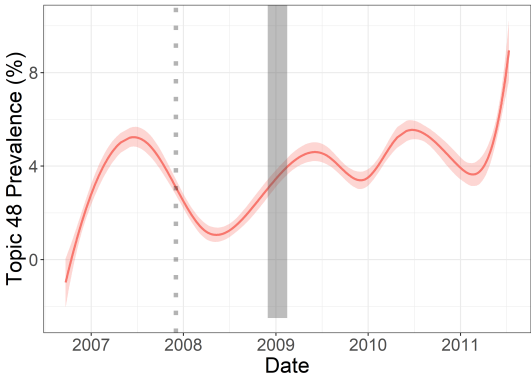

(b) Sports: Soccer

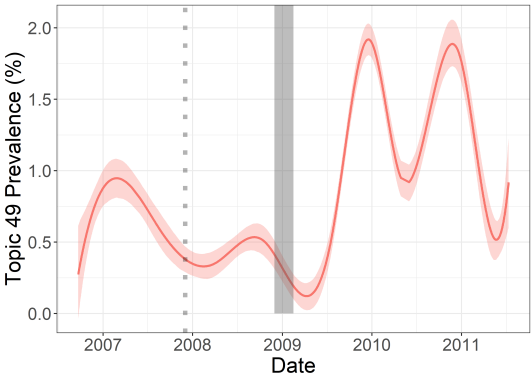

(c) Holidays

Figure 8: The Change of Average Topic Prevalence over Time: Distracting Topics

Note: The dotted line indicates the date of the first (failed) referendum (12/02/2007), and the gray area indicates the term limit evasion $(11 / 30 / 2008-02 / 15 / 2009)$.

This result is less likely to be attributed to exogenous sports events such as the Olympics. For example, the newspaper's attention to sports in late 2009 is greater than in 2008 , when the Beijing Olympics were held, and in early 2009, when the World Baseball Classic was held. This finding in part supports Hypothesis 2, positing that, due to government censorship, a media outlet has to find alternative interesting news instead of sensitive political issues. And such news distracts people's attention from more sensitive issues. 


\section{Conclusion}

Politicians often erode democratic institutions to consolidate their personal power through acts like term limit evasions. Violations of fundamental constitutional arrangements, so-called "bright line" institutions, are often expected to result in anti-government opposition. Then how do leaders evading term limits extend the term and keep their office? I argue that political leaders strategically prevent protests after the initiation of term limit evasions by limiting the free flow of information that is imperative for potential dissidents to collectively mobilize against a leader. Using difference-in-differences with matching for Time-Series Cross-Sectional data, I show that term limit evasions are followed by a marked decrease in a country's freedom of expression and it is more salient in autocracies than in democracies. In addition, using Venezuela as an example, I provide micro-evidence of information control by investigating how topics of opposition media change after term-limit evasion. Automated text analysis shows that a leader evading term limits not only censors threatening political information but also induces the media to offer distracting and apolitical information.

This article accounts for why would-be dictators attempt to keep their grip on media. Information control is one of the most effective ways to stymie anti-government movements during the erosion of democracy, and it makes a leader less likely to rely on explicit repression that may backfire (Gandhi 2008). Recent scholarly discussions center on the subversion of democratic institutions without threats of force or overt violence (Guriev and Treisman 2019, Levitsky and Ziblatt 2018, Svolik and Chernykh 2015). In line with the growing literature, this paper contends that a leader seeking indefinite tenure through term limit evasion uses a covert strategy, which is information control, to undermine the capabilities of potential dissidents to mobilize against the leader, thereby eroding democratic institutions.

This paper does not posit that controlling the free flow of information is the only way to hamper potential mass mobilization against a leader who evades term limits. Obviously, there may be other tactics would-be dictators use to repress anti-government actions. For example, after the initiation of a term limit evasion, some leaders may still have a penchant for using 
traditional repressive tools that prevent mass mobilization. Such repressive tools include the military, which is specialized in handling mass, violent, and organized mobilization (Brooks 2019, Svolik 2012), as well as traditional domestic repressors such as police and specialized internal security. President Lukashenko, in Belarus, for example, put considerable resources into the military after his first term limit extension in 2004 to thwart potential mobilization that was influenced by the color revolution and was challenging his legitimacy (Korosteleva 2012). Future research might investigate what other tools a leader may use to maintain control after term limit evasion. 


\section{References}

Afrobarometer. 2016. "Afrobarometer Round six data.".

URL: https://www.afrobarometer.org

Albertus, Michael and Victor Menaldo. 2012. "Dictators as founding fathers? The role of constitutions under autocracy." Economics \& Politics 24(3):279-306.

Baturo, Alexander. 2014. Democracy, dictatorship, and term limits. University of Michigan Press.

Bolt, Jutta, Robert Inklaar, Herman de Jong and Jan Luiten van Zanden. 2018. "Rebasing 'Maddison': New income comparisons and the shape of long-run economic development." Maddison Project Working paper 10.

URL: https://bit.ly/30R6Tt7

Borusyak, Kirill and Xavier Jaravel. 2017. "Revisiting event study designs.” Available at SSRN 2826228 .

Brooks, Risa A. 2019. "Integrating the civil-military relations subfield." Annual Review of Political Science 22:379-398.

Carey, John M. 2000. “Parchment, equilibria, and institutions.” Comparative Political Studies 33(6-7):735-761.

Casper, Brett Allen and Scott A Tyson. 2014. "Popular Protest and Elite Coordination in a Coup d'état.” The Journal of Politics 76(2):548-564.

Corrales, Javier. 2016. "Can anyone stop the president? Power asymmetries and term limits in Latin America, 1984-2016.” Latin American Politics and Society 58(2):3-25.

Davenport, Christian. 2007. “State repression and the tyrannical peace." Journal of Peace Research 44(4):485-504.

Daxecker, Ursula E. 2012. "The cost of exposing cheating: International election monitoring, fraud, and post-election violence in Africa." Journal of Peace Research 49(4):503-516.

De Angelis, Andrea and Alessandro Vecchiato. 2018. "Panem et Circenses: The Persuasive Effect of Soft News in Berlusconi's Italy.” Unpublished Manuscript, Available at SSRN 3245572 .

Denny, Matthew J and Arthur Spirling. 2018. "Text preprocessing for unsupervised learning: Why it matters, when it misleads, and what to do about it." Political Analysis 26(2):168-189.

Dixon, Rosalind and David Landau. 2019. "Constitutional End Games: Making Presidential Term Limits Stick.” Hastings Law Journal 71:359.

Dulani, Boniface Madalitso. 2011. Personal rule and presidential term limits in Africa. East Lansing: Michigan State University. 
Egorov, Georgy, Sergei Guriev and Konstantin Sonin. 2009. "Why resource-poor dictators allow freer media: A theory and evidence from panel data." American Political Science Review 103(4):645-668.

Fails, Matthew D. 2019. “Oil income and the personalization of autocratic politics." Political Science Research and Methods . DOI: https://doi.org/10.1017/psrm.2019.14.

Frantz, Erica, Andrea Kendall-Taylor, Joseph Wright and Xu Xu. 2020. "Personalization of Power and Repression in Dictatorships.” The Journal of Politics 82(1):372-377.

Gandhi, Jennifer. 2008. Political institutions under dictatorship. New York: Cambridge University Press.

Gehlbach, Scott and Konstantin Sonin. 2014. "Government control of the media." Journal of Public Economics 118:163-171.

Ginsburg, Tom, James Melton and Zachary Elkins. 2011. "On the evasion of executive term limits." William and Mary Law Review 52:1807-1872.

Gleditsch, Nils Petter, Peter Wallensteen, Mikael Eriksson, Margareta Sollenberg and Håvard Strand. 2002. "Armed conflict 1946-2001: A new dataset." Journal of Peace Research 39(5):615637.

Goemans, Henk E, Kristian Skrede Gleditsch and Giacomo Chiozza. 2009. "Introducing Archigos: A dataset of political leaders.” Journal of Peace Research 46(2):269-283.

Gohdes, Anita R. 2020. “Repression technology: Internet accessibility and state violence.” American Journal of Political Science.

Goodman-Bacon, Andrew. 2018. Difference-in-differences with variation in treatment timing. Technical report National Bureau of Economic Research.

Grimmer, Justin and Brandon M Stewart. 2013. "Text as data: The promise and pitfalls of automatic content analysis methods for political texts.” Political Analysis 21(3):267-297.

Griner, Steven. 2009. "Term limits can check corruption and promote political accountability." AMERICAS QUARTERLY (Spring) .

Guriev, Sergei and Daniel Treisman. 2019. “Informational autocrats.” Journal of Economic Perspectives 33(4):100-127.

Hardin, Russell. 1989. Why a Constitution. In The Federalist Papers and the New Institutionalism, ed. Bernard Grofman and Donald Wittman. Algora Publishing.

Ho, Daniel E, Kosuke Imai, Gary King and Elizabeth A Stuart. 2007. "Matching as nonparametric preprocessing for reducing model dependence in parametric causal inference." Political Analysis 15(3):199-236.

Huang, Haifeng. 2015. "Propaganda as signaling." Comparative Politics 47(4):419-444. 
Hyde, Susan D and Nikolay Marinov. 2014. "Information and self-enforcing democracy: The role of international election observation.” International Organization 68(2):329-359.

Imai, Kosuke and In Song Kim. 2020. "On the use of two-way fixed effects regression models for causal inference with panel data." Working Paper .

URL: http://web.mit.edu/insong/www/pdf/FEmatch-twoway.pdf

Imai, kosuke, In Song Kim and Erik Wang. 2020. "Matching methods for causal inference with time-series cross-sectional data." Working Paper.

URL: http://web.mit.edu/insong/www/pdf/tscs.pdf

King, Gary, Jennifer Pan and Margaret E Roberts. 2013. "How censorship in China allows government criticism but silences collective expression." American Political Science Review 107(2):326-343.

Korosteleva, Elena. 2012. "Questioning democracy promotion: Belarus' response to the 'colour revolutions.” Democratization 19(1):37-59.

Kropko, Jonathan and Robert Kubinec. 2020. "Interpretation and identification of within-unit and cross-sectional variation in panel data models.” PloS One 15(4):e0231349.

Kuran, Timur. 1991. "Now out of never: The element of surprise in the East European revolution of 1989.” World politics 44(1):7-48.

Levitsky, Steven and Daniel Ziblatt. 2018. How Democracies Die. Broadway Books.

Little, Andrew. 2016. "Communication Technology and Protest." The Journal of Politics 78(1):152-166.

Little, Andrew T. 2017. "Propaganda and credulity.” Games and Economic Behavior 102:224-232.

Lorentzen, Peter. 2014. “China's strategic censorship.” American Journal of Political Science 58(2):402-414.

Maltz, Gideon. 2007. “The case for presidential term limits.” Journal of Democracy 18(1):128142.

McKie, Kristin. 2019. "Presidential term limit contravention: Abolish, extend, fail, or respect?" Comparative Political Studies 52:1500-1534.

Negretto, Gabriel L. 2013. Making Constitutions: Presidents, Parties, and Institutional Choice in Latin America. Cambridge University Press.

Pettersson, Therése, Stina Högbladh and Magnus Öberg. 2019. “Organized violence, 1989-2018 and peace agreements.” Journal of Peace Research 56(4):589-603.

Poe, Steven C, C Neal Tate and Linda Camp Keith. 1999. "Repression of the human right to personal integrity revisited: A global cross-national study covering the years 1976-1993." International Studies Quarterly 43(2):291-313. 
Posner, Daniel N and Daniel J Young. 2018. "Term Limits: Leadership, Political Competition and the Transfer of Power." Institutions and Democracy in Africa: How the Rules of the Game Shape Political Developments pp. 260-278.

Qin, Bei, David Strömberg and Yanhui Wu. 2017. "Why does China allow freer social media? Protests versus surveillance and propaganda." Journal of Economic Perspectives 31(1):117-40.

Ritter, Emily Hencken and Courtenay R Conrad. 2016. "Preventing and Responding to Dissent: The Observational Challenges of Explaining Strategic Repression." American Political Science Review 110(1):85-99.

Roberts, Margaret E. 2018. Censored: Distraction and Diversion inside China's Great Firewall. Princeton, NJ: Princeton University Press.

Roberts, Margaret E, Brandon M Stewart and Dustin Tingley. 2019. "stm: R package for structural topic models." Journal of Statistical Software 10(2):1-40.

Ross, Michael L and Paasha Mahdavi. 2015. “Oil and Gas Data, 1932-2014.”. URL: https://doi.org/10.7910/DVN/ZTPWOY

Rozenas, Arturas and Denis Stukal. 2019. "How autocrats manipulate economic news: Evidence from Russia's state-controlled television.” The Journal of Politics 81(3):000-000.

Shadmehr, Mehdi and Dan Bernhardt. 2011. "Collective Action with Uncertain Payoffs: Coordination, Public Signals and Punishment Dilemmas.” American Political Science Review 105(04):829-851.

Shadmehr, Mehdi and Dan Bernhardt. 2015. "State censorship." American Economic Journal: Microeconomics 7(2):280-307.

Skaaning, Svend-Erik, John Gerring and Henrikas Bartusevičius. 2015. "A lexical index of electoral democracy." Comparative Political Studies 48(12):1491-1525.

Svolik, Milan W. 2012. The politics of authoritarian rule. Cambridge University Press.

Svolik, Milan W and Svitlana Chernykh. 2015. "Third-Party Actors and the Success of Democracy: How Electoral Commissions, Courts, and Observers Shape Incentives for Electoral Manipulation and Post-Election Protests." Journal of Politics 77(2):407-420.

Tucker, Joshua A. 2007. "Enough! Electoral fraud, collective action problems, and postcommunist colored revolutions.” Perspectives on Politics 5(3):535-551.

Versteeg, Mila, Timothy Horley, Anne Meng, Mauricio Guim and Marilyn Guirguis. 2020. "The Law and Politics of Presidential Term Limit Evasion." Columbia Law Review pp. 2019-14. 